\title{
Angiotensinergic innervation of rat and human mesenteric resistant blood vessels
}

Patil Jaspal, Heiniger Eva, Schaffner Thomas, Mühlemann Oliver and Imboden Hans

Institute of Cell Biology, University of Bern, Bern, Switzerland

Correspondence should be addressed to Imboden Hans (hans.imboden@izb.unibe.ch)

In contrast to the current believe that angiotensin II (Ang II) only interacts with the sympathetic nervous system (SNS) as a circulating hormone, we document here the existence of an endogenous renin-angiotensin system (RAS) in the sympathetic coeliac ganglion and the angiotensinergic innervation with mesenteric resistant blood vessels. Our findings indicate that Ang II is synthesized inside the neurons of sympathetic coeliac ganglion and may act as an endogenous neurotransmitter locally on the mesenteric resistant blood vessels.

Blood pressure control is predominantly regulated by the SNS and the RAS. The octapeptide Ang II is the effector component of the RAS and well known as a potent inducer of vasoconstriction, which leads to increased blood pressure and release of aldosterone from the adrenal cortex. Hormonal Ang II circulating in the blood has been reported to interact with the SNS at different sites and to directly stimulate the sympathetic activity ${ }^{1,3,6}$. Furthermore, it has been proposed that circulating Ang II functions at synaptic nerve endings e.g. with blood vessels by enhancing norepinephrine release and thereby facilitating sympathetic neurotransmission ${ }^{1,4,5}$. The presence of RAS components in circulation and at tissue level has been reported ${ }^{1}$, but the question of endogenous synthesis of Ang II in the SNS has not been addressed so far. Our study focused on the detection of different key components of RAS in sympathetic ganglions under normal physiological conditions. Thereby, we discovered the presence of an endogenous RAS in the normotensive rat sympathetic coeliac ganglion.

In order to demonstrate the synthesis of Ang II in the coeliac ganglion, we investigated the presence of key components of the RAS. Both, angiotensinogen (Ang-N) mRNA (Fig. 1a) and angiotensin converting enzyme (ACE) mRNA (Fig. 1c) was readily detected in total RNA extracts of rat coeliac ganglia by quantitative realtime RT-PCR (see Supplementary Methods online), whereas no renin mRNA could be traced (Fig. 1b). RNA from tissues with previously reported high levels of the respective mRNA was used as reference, and all mRNA values were normalised to $18 \mathrm{~S}$ rRNA. At single cell resolution, Ang-N mRNA was detected in nearly all of the neurons in the rat coeliac ganglion by in situ hybridization (see Supplementary Methods online) with the antisense probe (Fig. 1d), but not with the sense probe used as a control (Fig.1e). Immunocytochemical studies using our previously characterized monoclonal antibody against Ang II ${ }^{2}$ detected Ang II immunoreactivity in both the neuronal cytoplasm as well as in their projections in rat coeliac 
ganglia (Fig. 2a). In a transverse section of mesenteric resistance blood vessels, we can find strong angiotensinergic innervation (Fig. 2b). With confocal laser scanning microscopy (LSM), we were able to illustrate angiotensinergic synapses en passant (sympathetic varicosities) alongside the outer layer of vascular smooth muscle cells from rat (Fig. 2c-d). Likewise, we could also show the presence of Ang II in coeliac ganglia and mesenteric resistant blood vessels from human post mortem tissue (Fig. 3a-c).

Collectively, our results demonstrate expression of Ang-N and ACE mRNA in rat coeliac ganglia and the presence of Ang II in the cytoplasm of neurons of these coeliac ganglia, which suggests intracellular production of Ang II. Because we could not detect any renin expression in these neurons, the enzyme necessary for cleaving of Ang-N into the Ang I precursor of Ang II ${ }^{\mathbf{1}}$, we postulate that these neurons take up circulating renin to support synthesis of endogenous Ang II. This would be similar to cardiac tissue, where strong evidence exists for uptake of extracellular renin from the circulation $\mathbf{1 , 7 , 8 , 9}$.

In conclusion, our findings strongly indicate the existence of an endogenous RAS in the sympathetic coeliac ganglion and a direct angiotensinergic innervation with mesenteric resistant blood vessels. Since the presence of Ang II type 1 receptors on vascular smooth muscle cells has been reported ${ }^{\mathbf{1}}$, our findings support the hypothesis that neuronally produced Ang II is released through synapses en passant and plays an important role in the regulation of blood pressure.

Note: Supplementary information is available on the Nature Neuroscience website.

\section{ACKNOWLEDGMENTS}

We are grateful to Berne University Research Foundation, Swiss Society of Hypertension and AstraZeneca for financial support. M.O. is a fellow of the Cloëtta Foundation. We are also thankful to Susanne Gygax and Tina Wettmann for technical assistance.

1. Paul, M., Mehr, A.P. \& Kreutz, R. Physiol. Rev. 86, 747-803 (2006).

2. Frei, N. et al. Regul. Pept.101, 149-155 (2001).

3. Reid, I.A. Am. J. Physiol. 262, 763-778 (1992).

4. Suter, C. \& Coote, J.H. J. Auton. Nerv. Syst.19, 31-37 (1987).

5. Levens, N.R., Peach, M.J. \& Carey, R.M. J. Clin. Invest. 67, 1197-1207 (1981).

6. Lewis, G.P. \& Reit, E. J. Physiol.179, 538-553 (1965).

7. Danser, A.H. et al. Circulation 96, 220-226 (1997).

8. Schuijt, M.P. \& Danser, A.H. Am J. Hypertens.15, 1109-1116 (2002).

9. Peters, J. et al. Circ. Res. 90, 1135-1141 (2002). 
Figure 1 Determination of relative levels of angiotensinogen (Ang-N), renin and angiotensinogen converting enzyme (ACE) mRNA by quantitative realtime RT-PCR (RT-qPCR) and in situ hybridization of Ang-N mRNA in rat coeliac ganglia.

Reverse transcribed total RNA extracts of rat coeliac ganglia from different rats were tested by qPCR for the presence of Ang-N mRNA (a), for renin mRNA (b), and for ACE mRNA (c). Total RNA from liver (a), kidney (b), and lung (c) were used as a reference, respectively, and all relative mRNA values were normalized to $18 \mathrm{~S}$ rRNA levels. Average values and standard deviations of 4 qPCR measurements are shown. For in situ hybridization, $6 \mu \mathrm{m}$ thick consecutive paraffin sections were processed as described in supplementary methods. d) antisense probe. e) control with sense probe, revealing no staining. Bar: $50 \mu \mathrm{m}$.

Figure 2 Ang II immunoreactivity with rat coeliac ganglion, mesenteric resistant blood vessels and the presence of angiotensinergic synapses en passant.

Cryosections of $30 \mu \mathrm{m}$ thickness were incubated with our murine monoclonal anti Ang II antibody ${ }^{2}$, stained with goat anti-mouse $\left(\mathrm{GAM}^{\mathrm{Cy} 3}\right)$ in red and DAPI in blue for nuclei (see Supplementary Methods online). a) Ang II staining in neurons and their projections of coeliac ganglion. Bar: $10 \mu \mathrm{m}$. b) Ang II staining with a mesenteric resistant blood vessel, transverse section. Bar: $50 \mu \mathrm{m}$. c) Ang II staining with mesenteric resistant blood vessels, longitudinal section. Bar: $50 \mu \mathrm{m}$. d) Zoomed inset of panel c. Visualization of angiotensinergic synapses en passant (indicated by arrows). Bar: $10 \mu \mathrm{m}$.

Figure 3 Ang II immunoreactivity with human coeliac ganglion, mesenteric resistant blood vessels and presence of angiotensinergic synapses en passant.

Cryosections of $30 \mu \mathrm{m}$ thickness were stained as in Fig. 2. a) Ang II staining in neurons and projections of coeliac ganglion. Bar: $50 \mu \mathrm{m}$. b) Ang II staining with mesenteric resistant blood vessels. Bar: $50 \mu \mathrm{m}$. c) Zoomed inset of panel b. Visualization of angiotensinergic synapses en passant (indicated by arrows). Bar: $10 \mu \mathrm{m}$. 


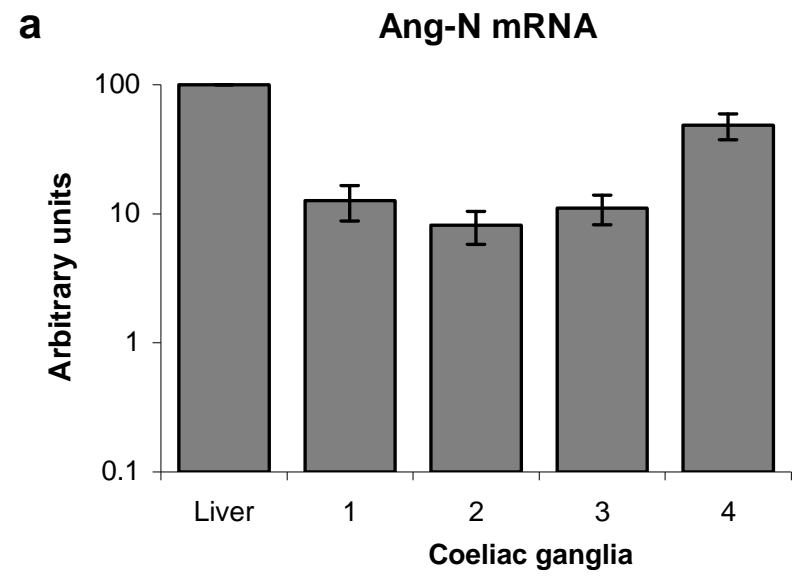

b Renin mRNA
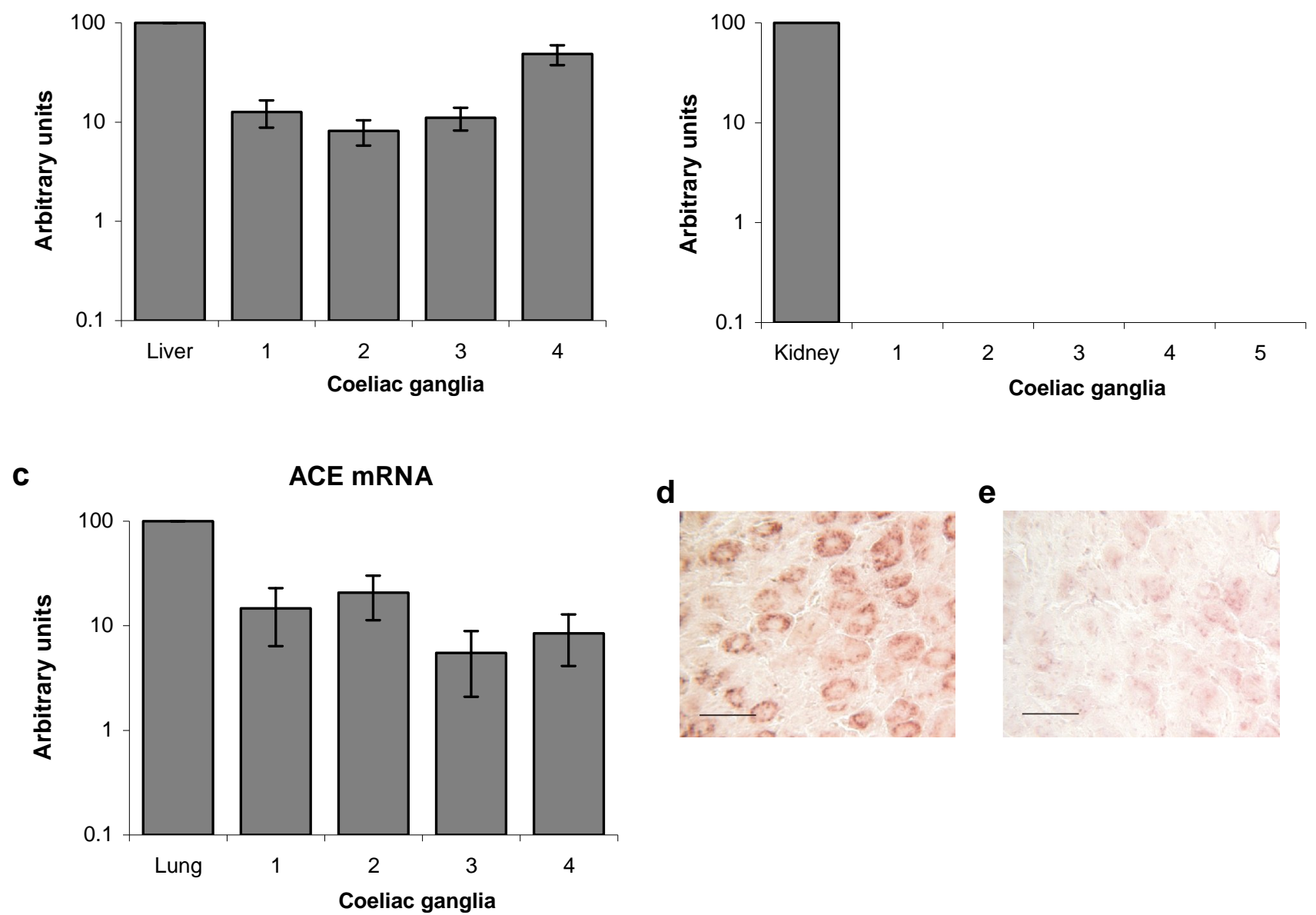

d

e

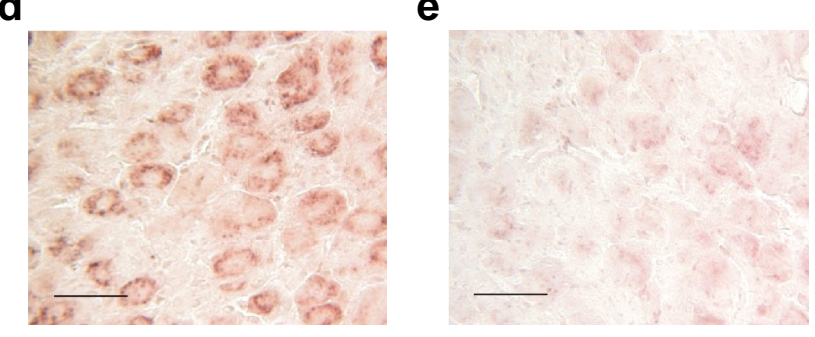

Figure 1. Imboden 2007 

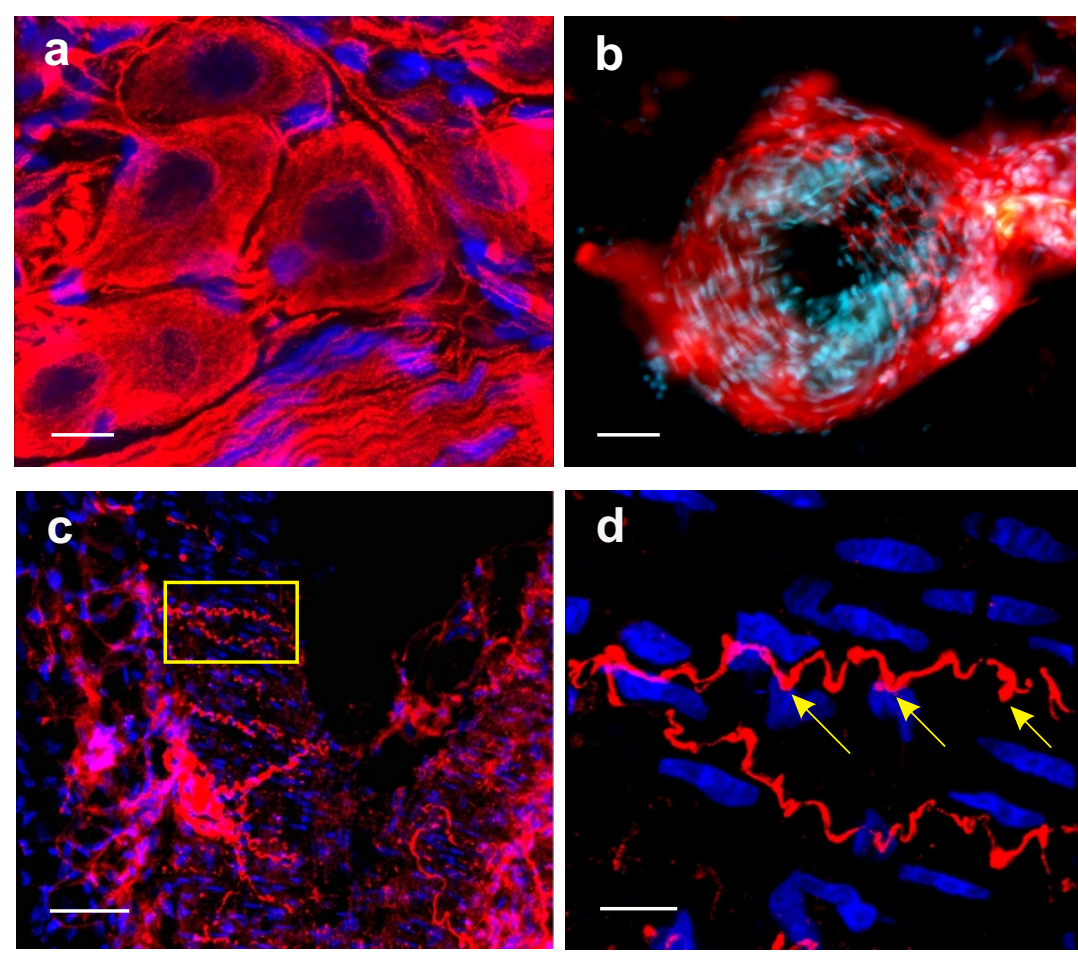

Figure 2. Imboden 2007 


\section{Supplementary methods}

Angiotensinergic innervation of rat and human mesenteric resistant blood vessels

Patil Jaspal, Heiniger Eva, Schaffner Thomas, Mühlemann Oliver and Imboden Hans

Institute of Cell Biology, University of Bern, Bern, Switzerland

\section{Tissue preparation}

Wistar Kyoto (WKY) male rats were purchased (8-week-old, approximately 200 gram body weight) from the Central Animal Facilities of the University of Bern. According to the European Communities Council Directive of 24 November 1986 (86/609/EEC) and in accordance with Animal Protocols approved by the Animal Care and Use Committee, NIMH, NIH, USA, adequate measures were taken to minimize pain or discomfort. Rats were anaesthetized intraperitoneally with $100 \mathrm{mg} / \mathrm{kg}$ thiopentane sodium (Pentothal, Abbott Laboratories, Germany) and were perfused transcardially with $150 \mathrm{ml}$ Ringer solution containing $1000 \mathrm{U}$ heparin at $37{ }^{\circ} \mathrm{C}$ followed by $300 \mathrm{ml} 2 \%$ freshly prepared formaldehyde at $4{ }^{\circ} \mathrm{C}$. Coeliac ganglia and mesenteric resistant blood vessels were carefully removed and incubated by immersion fixation in $2 \%$ formaldehyde for 28 hours at $4{ }^{\circ} \mathrm{C}$. Afterwards, coeliac ganglia and mesenteric blood vessels were immersed for 14 hours in phosphate-buffered saline containing $18 \%$ sucrose at $4{ }^{\circ} \mathrm{C}$. These tissues were frozen in isopentane at $-50{ }^{\circ} \mathrm{C}$ and cryosections of $30 \mu \mathrm{m}$ thicknesses were subsequently used free-floating for immunocytochemistry. After perfusion and immersion fixation, both rat tissues were also embedded in paraffin to perform additional experiments. $6 \mu \mathrm{m}$ thick paraffin sections were used for immunocytochemical and for in situ hybridization. Human coeliac ganglia and mesenteric resistant blood vessels were procured from human individuals for whom a permit for clinical autopsy (informed written consent by next of kin) had been obtained according to state law, in accordance with the Code of Ethics of the World Medical Association (Declaration of Helsinki). Human coeliac ganglia were fixed by immersion in freshly prepared $2 \%$ formaldehyde for 3 days and then used for cryosectioning or embedded in paraffin.

\section{RNA isolation and quantitative realtime RT-PCR}

Fresh rat coeliac ganglia were dissected as above and instantly transferred into RNA later (Ambion), frozen in liquid nitrogen, and then processed for the total RNA extraction (Ambion). RNA integrity was confirmed for each sample on the Agilent Bioanalyzer using the RNA 6000 Nano kit (Agilent Technologies). $1 \mu \mathrm{g}$ of total RNA was reverse transcribed using Supercript II (Invitrogen) and random hexamers according to the manufacturer's protocol. For realtime PCR, reverse transcribed material corresponding to 40 ng RNA was amplified with the TaqMan assays described below in $25 \mu \mathrm{l}$ Universal PCR Master Mix, No AmpErase UNG on the SDS 7000 (Applied Biosystems) using the standard thermal protocol. Average values and standard 
deviations of relative mRNA levels of each sample, normalized to relative $18 \mathrm{~S}$ rRNA levels, are from four measurements and were calculated using the relative differences.

The following TaqMan assays were used for realtime PCR at a final concentration of $250 \mathrm{nM}$ TaqMan probe and $900 \mathrm{nM}$ of each primer:

Angiotensinogen Forward primer 5'-CACGACTTCCTGACTTGGATAAAGA-3'; reverse primer 5'CTGCGGCAGGGTCAGA-3'; TaqMan probe 5'-FAM-CTCCTCGGGCCATCCG-MGB-3'; manufactured as Assays-by-Design (RATG-EJ3) by Applied Biosystems

Renin Assay-on-demand Rn00561847_m1 from Applied Biosystems

ACE Assay-on-demand Rn00561094_m1 from Applied Biosystems

$18 S$ rRNA: Predeveloped Assay Reagent 431-9413E from Applied Biosystems

\section{In situ hybridization}

\subsection{DIG-labelled RNA probe preparation}

By using an appropriate Ang-N cDNA template ${ }^{2}$, a 403 bp long fragment corresponding to nucleotides 221623 was generated by digestion with restriction enzymes EcoRV and BamHI. The obtained fragment was cloned between Stu I and Bam HI into pBluescript I KS+ (Stratagene). Digoxigenin-labelled probes were prepared using the DIG-RNA-labelling Mix (Roche, Basel, Switzerland) according to the manufacturer's protocol. T7 RNA polymerase was used to generate antisense riboprobe using the HindIII linearized template, and the sense strand (used as a control) was generated by T3 RNA polymerase using the same template linearized with BamHI. The RNA concentration was estimated comparing dot-blot tests and NanoDrop measurements. Filter hybridization with RNA extracts from coeliac ganglia (RNaqueous-4PCR kit from Ambion) was used for binding tests.

\subsection{In situ hybridization}

For in situ hybridization, $6 \mu \mathrm{m}$ thick paraffin sections were rehydrated in a graded alcohol series (2 times Xylol for $10 \mathrm{~min}$, EtOH $100 \%$ (2 times), $96 \%$, $70 \%$, $50 \%$, each step 5 min) using DEPC-treated $\mathrm{H}_{2} \mathrm{O}$ for the dilution of all reagents and solutions. The sections were equilibrated in proteinase $\mathrm{K}$ buffer (100 $\mathrm{mM}$ Tris, $50 \mathrm{mM}$ EDTA, $\mathrm{pH} 7.5)$ for 5 minutes and then treated with proteinase $\mathrm{K}(19 \mu \mathrm{g} / \mathrm{ml})$ at $37{ }^{\circ} \mathrm{C}$ for 2 minutes, after a wash with DEPC-treated $\mathrm{H}_{2} \mathrm{O}$. Following a wash in DEPC-water, sections were post fixed with freshly prepared $4 \%$ formaldehyde for 5 minutes, followed by two subsequent washes in DEPC-water for 5 minutes each. Sections were then incubated in prehybridization solution (SIGMA) at $45^{\circ} \mathrm{C}$ for 2 hours, followed by incubation with heat denatured sense and antisense riboprobes (5-10 ng/ $\mu \mathrm{l})$ in $30 \mu \mathrm{l}$ hybridization mix (SIGMA) for 48 hours at $45{ }^{\circ} \mathrm{C}$ in a humid chamber (saturated with $2 \mathrm{x}$ SSC). 
Subsequently, the sections were incubated with 2x SSC for 30 minutes at room temperature, followed by 1hour in $2 \mathrm{x} \mathrm{SSC}$ at $45^{\circ} \mathrm{C}$ and 1 hour in $0.1 \mathrm{x}$ SSC at $45^{\circ} \mathrm{C}$. Sections were equilibrated for 5 minutes with

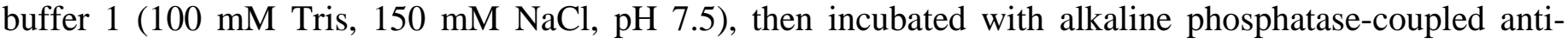
digoxigenin antibody (Roche) 1:500 diluted in buffer 2 (10x blocking solution diluted with buffer 1) for 2 hours at room temperature, followed by two 5 minutes washes with buffer 1. Finally, after 5 minutes equilibration with buffer $3(100 \mathrm{mM}$ Tris, $100 \mathrm{mM} \mathrm{NaCl}, 50 \mathrm{mM} \mathrm{MgCl}, \mathrm{pH} 9.5)$, the colour reaction containing NBT and BCIP in buffer 3 was completed according to manufacturer's protocol (Sigma).

\section{Immunocytochemistry}

For immunocytochemical incubations, our protein $\mathrm{G}$ purified murine monoclonal antibody against Ang II was used at a concentration of $0.3 \mu \mathrm{g} / \mathrm{ml}$ in buffer solution. This is a self-generated affinity purified monoclonal antibody against the synthetic peptide Ang II (4B3). The specificity for this monoclonal antibody against Ang II (4B3) has been previously documented and it produced the same staining as polyclonal antibody against Ang II in rat adrenal glands ${ }^{\mathbf{1}}$. Pre-absorption was performed by incubation with Ang II peptide covalently linked through its $\mathrm{N}$-terminus to $\mathrm{CH}$-Sepharose $4 \mathrm{~B}$. The gel was loaded into a glass column and the effluent was used for immunocytochemical controls. Incubations with this solution did not stain. Further controls, in which pre-immune mouse serum or the primary antibody has been omitted, also exhibited no staining. Goat anti-mouse immunoglobulins (GAM ${ }^{\mathrm{Cy} 3}$; Jackson ImmunoResearch) preincubated with rat serum prior to immunocytochemistry were used as secondary antibodies. Sections were incubated free floating for 36 hours at $4{ }^{\circ} \mathrm{C}$ with the primary antibody, washed and incubated with the secondary antibody for 90 minutes at room temperature. After washing, cryosections were counterstained with DAPI, mounted on gelatine-coated slides and air-dried. The stained sections were embedded with Glycergel (DAKO) and cover-slipped. The same procedure as for free floating cryosections has been used for paraffin sections mounted on glass slides. Pictures were taken by a normal fluorescent light microscope (LEICA DM 6000B) using a digital camera or by a confocal laser scanning microscope (LEICA SP2 with AOBS).

\section{References :}

1. Frei, N. et al. Regul. Pept.101, 149-155. (2001).

2. Lynch, K.R., Simnad, V.I., Ben-Ari, E.T. \& Garrison, J.C. Hypertension 8, 540-543. (1986). 